\title{
The improvement value and treatment safety of neurological rehabilitation strengthening training on upper limb functions of patients with cerebrovascular diseases
}

\author{
Fei YOU ${ }^{1 * \star}(\mathbb{D})$, Chaoyang $\mathrm{MA}^{1 *}$, Fen XU ${ }^{1}$, Fangfang $\mathrm{SUN}^{1}$, Wenjun $\mathrm{WAN}^{1 \star}$
}

\begin{abstract}
To explore the improvement value and treatment safety of neurological rehabilitation strengthening training on upper-limb functions of cerebrovascular patients. A total of 80 patients with cerebrovascular hemiplegia were divided into two groups. The 40 patients in the regular group were instructed to carry out regular rehabilitation training for $20 \mathrm{~min} /$ day, lasting for $5 \mathrm{~d} /$ week; another 40 patients in the strengthening group were instructed to carry out neurological rehabilitation strengthening training on the basis of regular training. Before the intervention, there was no significant difference in fma-ue, ARAT, MBI scores and EDV, RI, PSV of carotid and vertebral arteries between the two groups (P > 0.05); after treatment, fma-ue, ARAT, MBI, EDV, PSV of the study group were higher than those of the control group, RI was less than that of the control group, the differences were statistically significant $(\mathrm{P}<0.05)$, after the intervention, the number of patients with grade IV $\sim$ VI in the study group was more than that of the control group, the difference was statistically significant $(\mathrm{P}<0.05)$. The application of neurological rehabilitation strengthening training might improve the upper-limb motor functions of patients with cerebrovascular hemiplegia and promote the rehabilitation of limb nerve functions.
\end{abstract}

Keywords: neurological rehabilitation strengthening training; cerebrovascular disease; stroke; upper-limb function; rehabilitation; safety.

Practical Application: Neurological Rehabilitation Strengthening Training on Upper Limb Functions.

\section{Introduction}

Cerebrovascular disease is referred to various diseases that occurs in brain blood vessels, including cerebral atherosclerosis, thrombosis, stenosis, occlusion, cerebral arteritis, cerebral artery injury, cerebral aneurysms and intracranial vascular malformations, cerebral arteriovenous fistula pathological changes and etc. whose common characteristic is causing ischemic or hemorrhagic accident in brain tissues, such as cerebral infarction, cerebral hemorrhage and etc., which may easily lead to disability or death of patients (Lanzino \& Brown, 2014; Caplan et al., 2009). China has the highest incidence of stroke in the world, and about $70 \%$ of the survivors of stroke suffer from disability to different degrees, including limb numbness, paralysis, swallowing and language dysfunction, and urination disorders, etc., which not only affects the patients' daily life, but also endangers their safety of life (Wu et al., 2019).

At present, it is clinically believed that brain plasticity and brain function recombination theory are the important basis for functional rehabilitation after central nervous system injury, and the disability of cerebrovascular patients is mainly caused by cerebral cortex, pyramidal tract, sensory conduction tract and other nerve damages (Lu et al., 2015; Wang et al., 2021; Lee et al., 2020). A large number of studies have shown that repeated limb movement training courses will promote the regeneration and reorganization of nerve circuits effectively and strengthen the connections between synapses, so as to rehabilitate nerve functions and body functions. Hence, the rehabilitation therapy concept of strengthening exercise has been proposed (SandrowFeinberg \& Houlé, 2015). It was considered that a client-centered treatment might offer a solution to the wide range of upper extremity activities and the importance of the specificity of the training (Spooren et al., 2009; Aydogan-Coskun et al., 2020). The aim of the study is to explore the improvement value and treatment safety of strengthened training mode of neurological rehabilitation on the upper-limb function of cerebrovascular disease patients through comparative analysis.

\section{Methods}

\subsection{General data}

This is a prospective open label study. A total of 80 patients with cerebrovascular hemiplegia who received treatment in our hospital from March 2018 to September 2019 were randomly selected and divided into the regular group and strengthening group by computerized randomization, for 40 cases in each group respectively. Inclusion criteria: complying with the relevant diagnostic criteria for stroke of China and diagnosed through cranial CT or MRI; the vital signs are stable and there are hemiplegia symptoms; age $\geq 50$ years; with normal cognitive function, signed the informed consent voluntarily. Exclusion criteria: patients with

${ }^{1}$ Department of Rehabilitation Medicine, The Central Hospital of Wuhan, Tongji Medical College, Huazhong University of Science and Technology, Wuhan, Hubei, China

\# The First Author

*Corresponding author: youyou7410@21cn.com 
bilateral lesions; patients with serious complications; transient cerebral ischemia and arachnoid space hemorrhage; patients with severe lesions of main internal organs; incomplete clinical data and follow-up of patients with drop-out. This research project has been submitted to and approved by the Ethics Committee.

\subsection{Research method}

Regular group

All patients received basic treatment after enrollment, and the regular rehabilitation training methods mainly included finger and wrist movement training. The rehabilitation therapist instructed and assisted the patients in the passive movement of thumb and other four fingers in turn and conducted two-hand grasping training. Rood technique was used to induce active back extension and finger extension of the wrist joint in patients with hemiplegia. The training time is $20 \mathrm{~min} / \mathrm{d}, 5 \mathrm{~d} /$ week; with the instructions of rehabilitation therapist, the patients could carry out the movement activities independently, such as the affected-side ring, plug-in, frosting board and pushing roller, accompanied by the transfer ability training, and the patients were instructed to take the initiative to carry out daily living ability training.

\section{Strengthening group}

After the patients were enrolled, the strengthening training mode was added on the basis of the conventional rehabilitation training: increase early-stage bedside rehabilitation training. Passive limb movements were performed on patient, while the patient was in the supine position. From top to bottom, the affected side shoulder joint, elbow joint and metacarpophalangial joint as well as the painless range were gently passive activity intervention, and contracture inclined to the opposite direction of training activities, such as shoulder abduction, abduction and forearm backrotation were mostly carried out. The patient could be guided to do more activities during active exercise, and the upper limbs can be trained through crossed fingers, clenched hands, arm lifting and other movements for about $20 \mathrm{~min}$, and guide patients with anterior flexion after stretching and outreach adduction and practice, it is the former supine position, the latter in lateral position, the stretch of elbow and wrist joints, puts the same shoulder joint to flexion position, let the victim from the back to go on active power control shoulder joint activity, $90^{\circ}$ bend forward, rehabilitation physician hand wrist and elbow, the line between $90^{\circ}-180^{\circ}$ joint activities. When it is confirmed that the patient can carry out the above control activities by himself, the range of motion can be extended to the shoulder joint flexion position movement, $8 \mathrm{~min}$ each time, once a day. After that, the difficulty and intensity of good activities can be appropriately increased according to the patient's recovery. When the patient is able to get out of bed, he or she is guided to walk and to move up and down the stairs. Followup training guidance was given to patients before discharge, and intensive training after discharge was encouraged to adhere to functional training. The regular rehabilitation training and the strengthening training were administrated for the inpatients at 24 hours after stroke.

\subsection{Evaluation index}

Both groups of patients were given rehabilitation training for 3 months and followed up. The recovery of upper limb function was compared between the two groups, and Fugl-Meyer upperlimb motor functions (FMA-UE), Action Research Arm Test (ARAT) score and Modified Barthel Index (MBI) (Aida et al., 2018) were compared before and after treatment, and the excellent and good rates of rehabilitation treatment were collected and the adverse reactions during treatment were observed.

FMA-UE score scale includes nine motor function tests, including upper-limb reflex activity, flexor joint movement, extensor joint movement, activity accompanied by joint movement, and separation movement. The total score was 66 points, and the higher the score, the better the upper-limb motor function of patients.

ARAT scale contains four subitems of grasping, holding, pinching and gross movements, with a total of 19 subitems. The 4-level scoring was used, zero point is classified as unable to complete the movements, 3 points as able to complete the movements normally, and the total score is classified as 57 points. The higher the score, the better the completion of the upper-limb movements.

MBI index consists of 11 items, with zero point being completely dependent and 10 points being completely independent. The evaluation is based on the actual daily performance of patients. The lower the score is, the more serious the dysfunction of daily life is; the higher the score is, the less the dysfunction is, and the better the independence of life is.

The changes of Brunnstrom's upper limb function rating before and after rehabilitation were compared between the two groups. Brunnstrom grading standard was used: Grade I was weakness of upper limb, without reflex and active movement; Grade II: slight flexion of upper limb, joint movement and spasm; In grade III, the upper limbs can cause joint movement at will; In grade IV, the upper limbs can move actively and the spasm is weakened; In grade V, the upper limbs can move independently and are not affected by the movement mode; Grade VI upper limbs can move normally, joints can move independently, and coordination is good.

\subsection{Statistical analysis}

SPSS 20.0 software was used for statistical processing of the study data. The categorical variables were represented by (\%), and Chi-square for inspection, while the continuous variables were represented by $\mathrm{x} \pm \mathrm{s}$, and " $\mathrm{t}$ " for inspection. The comparison between the two groups was performed using Student T test. $\mathrm{P}<0.05$ was set as statistically difference.

\section{Results}

\subsection{Comparison of general data of patients in the two groups}

In the regular group, there were 23 males and 17 females, with an average age of $67.28 \pm 6.34$ years, including 15 cases of cerebral infarction, 9 cases of cerebral hemorrhage and 6 cases of other cerebrovascular diseases; In the strengthening group, 
there were 24 males and 16 females, with an average age of $67.85 \pm 6.52$ years, including 16 cases of cerebral infarction, 7 cases of cerebral hemorrhage and 7 cases of other cerebrovascular diseases. The above general data of the two groups were compared and analyzed as shown in Table 1. There were no statistically significant differences in the general data of gender, age and stroke type between the strengthening group and the regular group $(\mathrm{P}>0.05)$, indicating comparability.

\subsection{Comparison of upper limb function recovery between two groups before and after rehabilitation treatment}

There was no significant statistical difference in FMA-UE score, ARAT score and MBI index between the strengthening group and the regular group $(\mathrm{P}>0.05)$ before treatment; after treatment, the scores of patients in both groups were improved, and the scores of patients in the strengthening group were significantly higher than those in the control group, with statistically significant differences between the two groups $(\mathrm{P}<0.05)$, as shown in Table 2.

\subsection{Comparison of hemodynamic indexes of carotid and vertebral artery before and after treatment}

There was no significant difference in EDV, RI and PSV between the two groups before intervention, but EDV and PSV in the study group were higher than those in the control group, and RI was lower than that in the control group $(\mathrm{P}<0.05)$, as shown in Table 3.

\subsection{Comparison of upper limb Brunnstrom grades between two groups before and after treatment}

There was no significant difference between the two groups $(\mathrm{P}>0.05)$. After the intervention, the number of grade II -III in the two groups decreased, and the number in grade iii increased, the study group was more than the control group, the difference was statistically significant $(\mathrm{P}<0.05)$, as shown in Table 4 .

Table 1. Comparative Analysis of General Data of Patients in the Two Groups (\%, $\bar{x} \pm s$ ).

\begin{tabular}{lccccc}
\hline & & Regular group & Strengthening group & $\mathrm{x}^{2} / \mathrm{t}$ & \\
\hline Number & & 40 & 40 & & \\
Gender Composition [n (\%)] & Men & $23(57.5)$ & $24(60.0)$ & 0.129 & 0.72 \\
& Women & $17(42.5)$ & $16(40.0)$ & 0.396 & 0.359 \\
Mean Age (years) & & $67.28 \pm 6.34$ & $67.85 \pm 6.52$ & 16 & 0.836 \\
Disease Type [n (\%)] & Cerebral Infarction & 15 & 7 & & \\
& Cerebral Hemorrhage & 9 & 6 & & \\
& Others & 6 & & \\
\hline
\end{tabular}

Note: $\mathrm{n}$ is an example, $\mathrm{x}^{2}$ is a measure of the difference between the actual value and the theoretical value, and $\mathrm{t}$ is the statistical analysis subject to $\mathrm{t}$ distribution to test the average values of two normal populations; $\mathrm{P}$ is the probability of occurrence of a sample observation or more extreme result if the original hypothesis is true.

Table 2. Comparison of upper limb function recovery between two groups before and after rehabilitation.

\begin{tabular}{|c|c|c|c|c|c|c|c|c|}
\hline \multirow[b]{2}{*}{ Time } & \multicolumn{2}{|c|}{ Regular group $(n=40)$} & \multicolumn{2}{|c|}{ Strengthening group $(n=40)$} & \multicolumn{2}{|c|}{$t$} & \multicolumn{2}{|c|}{$P$} \\
\hline & $\begin{array}{c}\text { Before } \\
\text { treatment }\end{array}$ & $\begin{array}{c}\text { After } \\
\text { treatment }\end{array}$ & $\begin{array}{c}\text { Before } \\
\text { treatment }\end{array}$ & $\begin{array}{c}\text { After } \\
\text { treatment }\end{array}$ & $\begin{array}{c}\text { Before } \\
\text { treatment }\end{array}$ & $\begin{array}{c}\text { After } \\
\text { treatment }\end{array}$ & $\begin{array}{c}\text { Before } \\
\text { treatment }\end{array}$ & $\begin{array}{c}\text { After } \\
\text { treatment }\end{array}$ \\
\hline FMA-UE & $36.25 \pm 3.49$ & $43.57 \pm 2.96^{*}$ & $36.20 \pm 3.67$ & $59.32 \pm 3.68^{\star}$ & 0.062 & 21.092 & 0.95 & 0.001 \\
\hline ARAT & $36.03 \pm 2.12$ & $44.18 \pm 2.54^{\star}$ & $36.14 \pm 2.33$ & $51.34 \pm 2.88^{\star}$ & 0.221 & 11.793 & 0.826 & 0.001 \\
\hline MBI & $61.04 \pm 6.73$ & $70.02 \pm 6.58^{*}$ & $60.15 \pm 6.29$ & $78.05 \pm 4.26^{*}$ & 0.611 & 6.493 & 0.543 & 0.001 \\
\hline
\end{tabular}

${ }^{\star}$ Compared with that before treatment, the difference within the group, $\mathrm{P}<0.05$. FMA-UE $=$ Fugl-Meyer upper-limb motor functions; MBI $=$ Modified Barthel Index; ARAT $=$ Action Research Arm Test. Dara were expressed as mean \pm standard deviation.

Table 3. Comparison of hemodynamic indexes of carotid and vertebral artery before and after treatment.

\begin{tabular}{|c|c|c|c|c|c|}
\hline \multirow{2}{*}{\multicolumn{2}{|c|}{$\begin{array}{c}\text { Group } \\
\text { Time }\end{array}$}} & \multicolumn{2}{|c|}{ Regular group $(n=40)$} & \multicolumn{2}{|c|}{ Strengthening group $(\mathrm{n}=40)$} \\
\hline & & Before treatment & After treatment & Before treatment & After treatment \\
\hline \multirow[t]{3}{*}{ Carotid artery } & $\operatorname{EDV}(\mathrm{cm} / \mathrm{s})$ & $16.23 \pm 4.82$ & $18.83 \pm 4.96^{* \#}$ & $16.34 \pm 4.90$ & $17.95 \pm 5.21^{\star}$ \\
\hline & $\operatorname{PSV}(\mathrm{cm} / \mathrm{s})$ & $67.51 \pm 15.49$ & $72.43 \pm 14.25^{\star *}$ & $67.94 \pm 15.68$ & $70.16 \pm 15.16^{*}$ \\
\hline & RI & $0.73 \pm 0.09$ & $0.62 \pm 0.11^{\star \#}$ & $0.70 \pm 0.10$ & $0.66 \pm 0.17^{\star}$ \\
\hline \multirow[t]{3}{*}{ Vertebral artery } & $\operatorname{EDV}(\mathrm{cm} / \mathrm{s})$ & $12.83 \pm 4.51$ & $14.55 \pm 4.46^{\star \#}$ & $12.92 \pm 4.60$ & $13.49 \pm 4.73^{*}$ \\
\hline & $\operatorname{PSV}(\mathrm{cm} / \mathrm{s})$ & $55.85 \pm 13.29$ & $58.49 \pm 14.16^{* \#}$ & $56.03 \pm 12.37$ & $57.22 \pm 14.58$ \\
\hline & RI & $0.73 \pm 0.11$ & $0.61 \pm 0.09^{* \#}$ & $0.71 \pm 0.09$ & $0.67 \pm 0.10^{*}$ \\
\hline
\end{tabular}

${ }^{\star}$ Compared with the control group before treatment $\mathrm{P}<0.05$; ${ }^{*}$ Compared with the control group after treatment $\mathrm{P}<0.05$. Dara were expressed as mean \pm standard deviation. 
Table 4. Comparison of upper limb Brunnstrom grades between two groups before and after treatment.

\begin{tabular}{|c|c|c|c|c|c|c|c|c|}
\hline Group & Regular & $\mathrm{p}(\mathrm{n}=40)$ & Strengthen & roup $(\mathrm{n}=40)$ & $x^{2}$ & $P$ & $x^{2}$ & $P$ \\
\hline Time & $\begin{array}{c}\text { Before } \\
\text { treatment }\end{array}$ & $\begin{array}{c}\text { After } \\
\text { treatment }\end{array}$ & $\begin{array}{c}\text { Before } \\
\text { treatment }\end{array}$ & $\begin{array}{c}\text { After } \\
\text { treatment }\end{array}$ & $\begin{array}{c}\text { Before } \\
\text { treatment }\end{array}$ & $\begin{array}{c}\text { Before } \\
\text { treatment }\end{array}$ & $\begin{array}{c}\text { After } \\
\text { treatment }\end{array}$ & $\begin{array}{c}\text { After } \\
\text { treatment }\end{array}$ \\
\hline Stage-II & $10(25.00)$ & $8(20.00)$ & $11(27.50)$ & $4(10.00)$ & 0.161 & 0.688 & 3.922 & 0.048 \\
\hline Stage-III & $9(22.50)$ & $7(17.50)$ & $8(20.00)$ & $4(10.00)$ & 0.187 & 0.666 & 2.372 & 0.124 \\
\hline Stage-IV & $11(27.50)$ & $12(30.00)$ & $12(30.00)$ & $16(40.00)$ & 0.153 & 0.696 & 2.198 & 0.138 \\
\hline Stage-V & $10(25.00)$ & $12(30.00)$ & $9(22.50)$ & $11(27.50)$ & 0.173 & 0.678 & 0.153 & 0.696 \\
\hline Stage-VI & $0(0.00)$ & $1(2.50)$ & $0(0.00)$ & $5(12.50)$ & - & - & 7.207 & 0.007 \\
\hline
\end{tabular}

Data were expressed as $\mathrm{n}(\%)$.

\section{Discussion}

The clinical incidence, mortality and disability rate of cerebrovascular diseases are all at a high level, which has become an important medical problem of worldwide concern. As a country with a large population, China ranks first in the world in terms of morbidity and invests up to 10 Billion CNY in medical expenses related to such diseases every year. Cerebrovascular diseases bring heavy economic burden to individuals, society and the country (Sakzewski et al., 2019). Cerebral atherosclerosis, thrombosis, stenosis, occlusion, inflammation and other pathological changes are the main basis of cerebrovascular disease which causes serious damage to the nervous system of the body. The investigations have shown that only $3 \%$ to $10 \%$ of stroke patients may recover life status to the onset of the disease one year after the onset, and about $30 \%$ of patients still suffer from the disability caused by brain injury, and limb dysfunction makes them unable to move or even completely unable to take care of themselves (In et al., 2018). Patients with hemiplegia caused by various cerebrovascular diseases not only suffer from the dysfunction of movement, sensation and spirit brought by the central nervous system injury, but also face a series of problems from the society and living, resulting in large family pressure. It is of great practical significance to continuously explore an effective rehabilitation measure to help cerebrovascular patients improve motor functions and promote the rehabilitation of nervous system, which will improve their own quality of life, reduce family pressure, and alleviate the overall burden of society.

Strengthening the concept of exercise is one of the contents of rehabilitation treatment, which usually includes increasing training time and training intensity. The former mainly refers to increasing training amount or total time, while the latter refers to increasing training frequency (Bang et al., 2018). Repeated exercise training will promote the recombination of neural circuits in the brain of cerebrovascular patients and improve the efficiency of synaptic reconnection. After establishing a normal exercise pattern, patients with hemiplegia must strengthen and maintain this pattern through repeated training (Bae \& Kim, 2017). In this study, hemiplegia patients with cerebrovascular disease were selected as the objects, to explore the improvement of their upper-limb motor function, so neurological rehabilitation strengthening training mode and regular rehabilitation treatment were applied for comparative analysis. The data showed that FMA-UE score and ARAT score of the patients in the strengthening group were significantly higher than those in the regular group after rehabilitation treatment, verifying that the program in this group was effective in improving the upper-limb motor function of the patients; The MBI index of patients in the strengthening group was higher than the regular group, indicating that the daily living ability of patients with cerebrovascular disease hemiplegia was improved through strengthened rehabilitation treatment. The neurological rehabilitation strengthening training focuses more on seizing the opportunity and advantage of patients' early rehabilitation training to intervene in patients. At the same time, it is more scientific and effective to exercise the patients' function in the later rehabilitation training process, with gradually increased rated of training intensity to accelerate the recovery of patients' limb function and enable patients to experience the joy of success, which will also help strengthen rehabilitation and improve the enthusiasm and initiative of rehabilitation training (Aprile et al., 2017). In the process of training, functional training opposite to the direction of contracture can effectively improve the contracture phenomenon of muscles in patients who are unable to carry out limb movements, reduce the difficulty in later rehabilitation, and improve the rehabilitation effect of patients better (Naghavi \& Wade, 2019). In addition, there are individual differences between persons who should not treat as the same in rehabilitation therapy under a unified and rigid training plan. In the course of intensive training, the adjustment of training intensity according to patients' conditions enhances the pertinence and specificity of rehabilitation treatment, which is in line with the modern concept of precision medicine. Clinically, there are some rehabilitation exercises that introduce manipulator into treatment training, a way of strengthening training, The manipulator also increases the input of sensory information and plays a good role in promoting the regeneration of the patients' nerve collateral and the establishment of connections between nerve axon synapses, so that the damaged brain can be reshaped and recombined (Chen et al., 2018). According to the theory of nerve physiology, motor learning and rehabilitation lie in repetitive motion form, while the brain judges and integrates information, with effective control and feedback information to adjust the movement pattern, namely the formation of optimization of neural network and exercise program, having a positive effect on the adaptability, feedforward ability and coordination of brain (Mazzoleni et al., 2014). In recent years, the neurological rehabilitation system has been applied to regular family rehabilitation training in foreign countries, which has achieved good outcomes in improving hand flexibility, muscle contractility and joint range of motion and etc (Best et al., 2018). This indicates that neurological rehabilitation strengthening training has a favorable effect on improvement of joint and limb functions of patients, and also suggests the importance of combining good rehabilitation concepts with 
patients' rehabilitation at home, which provides a direction for future research. The study also indicates that the application of neurological rehabilitation system is effective in promoting the recovery of upper-limb motor functions in patients with cerebrovascular hemiplegia.

There were also some limitations of this study. First, the sample size has not been precalculated in this study and it was relatively small. Therefore, there might be lack of power in this study, which could affect the accuracy of our results. Second, other physiological parameters, which may affect the results and variation, were not evaluated in this study. Third, the adherence of patients was not regularly evaluated.

In conclusion, the application of neurological rehabilitation strengthening training, on the basis of regular rehabilitation treatment, might improve the upper-limb motor functions of patients with cerebrovascular hemiplegia, and promote the rehabilitation of limb nerve functions. Meanwhile, it's safer and worthy of promotion in clinical practice.

\section{Conflict of interest}

The authors declare that they have no conflict of interest.

\section{References}

Aida, J., Chau, B., \& Dunn, J. (2018). Immersive virtual reality in traumatic brain injury rehabilitation: a literature review. NeuroRehabilitation, 42(4), 441-448. http://dx.doi.org/10.3233/NRE-172361. PMid:29660958.

Aprile, I., Iacovelli, C., Padua, L., Galafate, D., Criscuolo, S., Gabbani, D., Cruciani, A., Germanotta, M., Di Sipio, E., De Pisi, F., \& Franceschini, M. (2017). Efficacy of Robotic-Assisted Gait Training in chronic stroke patients: preliminary results of an Italian bi-centre study. NeuroRehabilitation, 41(4), 775-782. http://dx.doi.org/10.3233/ NRE-172156. PMid:28946585.

Aydogan-Coskun, B., Coklar, H., \& Akbulut, M. (2020). Effect of heat treatment for liquefaction and pasteurization on antioxidant activity and phenolic compounds of Astragalus and sunflower-cornflower honeys. Food Science and Technology, 40(3), 629-634. http://dx.doi. org/10.1590/fst.15519.

Bae, S., \& Kim, K. Y. (2017). Dual-afferent sensory input training for voluntary movement after stroke: a pilot randomized controlled study. NeuroRehabilitation, 40(3), 293-300. http://dx.doi.org/10.3233/ NRE-161417. PMid:28222553.

Bang, D. H., Shin, W. S., \& Choi, H. S. (2018). Effects of modified constraint-induced movement therapy with trunk restraint in early stroke patients: a single-blinded, randomized, controlled, pilot trial. NeuroRehabilitation, 42(1), 29-35. http://dx.doi.org/10.3233/NRE172176. PMid:29400671.

Best, J. R., Eng, J. J., Davis, J. C., Hsiung, R., Hall, P. A., Middleton, L. E., Graf, P., Goldsmith, C. H., \& Liu-Ambrose, T. (2018). Study protocol for vitality: a proof-of-concept randomised controlled trial of exercise training or complex mental and social activities to promote cognition in adults with chronic stroke. BMJ Open, 8(3), e021490. http://dx.doi.org/10.1136/bmjopen-2018-021490. PMid:29550783.

Caplan, L. R., Searls, D. E., \& Hon, F. K. (2009). Cerebrovascular disease. The Medical Clinics of North America, 93(2), 353-369, viii. http:// dx.doi.org/10.1016/j.mcna.2008.09.004. PMid:19272513.

Chen, J., Liu, M., Sun, D., Jin, Y., Wang, T., \& Ren, C. (2018). Effectiveness and neural mechanisms of home-based telerehabilitation in patients with stroke based on fMRI and DTI: A study protocol for a randomized controlled trial. Medicine, 97(3), e9605. http://dx.doi.org/10.1097/ MD.0000000000009605. PMid:29504985.

In, T., Jung, K., Lee, M. G., \& Cho, H. Y. (2018). Whole-body vibration improves ankle spasticity, balance, and walking ability in individuals with incomplete cervical spinal cord injury. NeuroRehabilitation, 42(4), 491-497. http://dx.doi.org/10.3233/NRE-172333. PMid:29660953.

Lanzino, G., \& Brown, R. D. Jr. (2014). Introduction: management of ischemic cerebrovascular disease. Neurosurgical Focus, 36(1), 1-2. http://dx.doi.org/10.3171/2013.11.FOCUS13513. PMid:24380487.

Lee, S. H., Yeo, D., \& Hong, J. H. (2020). Effect of dihydroferulic acid obtained from fermented rice bran extract on neuroprotection and behavioral recovery in an ischemic rat model. Food Science and Technology, 40(Suppl. 2), 475-481. http://dx.doi.org/10.1590/fst.33719.

Lu, X., Battistuzzo, C. R., Zoghi, M., \& Galea, M. P. (2015). Effects of training on upper limb function after cervical spinal cord injury: a systematic review. Clinical Rehabilitation, 29(1), 3-13. http://dx.doi. org/10.1177/0269215514536411. PMid:25575932.

Mazzoleni, S., Puzzolante, L., Zollo, L., Dario, P., \& Posteraro, F. (2014). Mechanisms of motor recovery in chronic and subacute stroke patients following a robot-aided training. IEEE Transactions on Haptics, 7(2), 175-180. http://dx.doi.org/10.1109/TOH.2013.73. PMid:24968381.

Naghavi, N., \& Wade, E. (2019). Prediction of Freezing of Gait in Parkinson's Disease Using Statistical Inference and Lower-Limb Acceleration Data. IEEE Transactions on Neural Systems and Rehabilitation Engineering, 27(5), 947-955. http://dx.doi.org/10.1109/ TNSRE.2019.2910165. PMid:30990186.

Sakzewski, L., Bleyenheuft, Y., Boyd, R. N., Novak, I., Elliott, C., Reedman, S., Morgan, C., Pannek, K., Fripp, J., Golland, P., Rowell, D., Chatfield, M., \& Ware, R. S. (2019). Protocol for a multisite randomised trial of Hand-Arm Bimanual Intensive Training Including Lower Extremity training for children with bilateral cerebral palsy: HABIT-ILE Australia. BMJ Open, 9(9), e032194. http://dx.doi. org/10.1136/bmjopen-2019-032194. PMid:31501133.

Sandrow-Feinberg, H. R., \& Houlé, J. D. (2015). Exercise after spinal cord injury as an agent for neuroprotection, regeneration and rehabilitation. Brain Research, 1619, 12-21. http://dx.doi.org/10.1016/j. brainres.2015.03.052. PMid:25866284.

Spooren, A. I., Janssen-Potten, Y. J., Kerckhofs, E., \& Seelen, H. A. (2009). Outcome of motor training programmes on arm and hand functioning in patients with cervical spinal cord injury according to different levels of the ICF: a systematic review. Journal of Rehabilitation Medicine, 41(7), 497-505. http://dx.doi.org/10.2340/16501977-0387. PMid:19543659.

Wang, L., Liu, G., Shao, Z., Zhang, Q., Yin, L., Xu, E., Li, B., Cui, X., \& Teng, H. (2021). MicroR-146 protects against rat ischemia-reperfusion injury by targeting NF- $\kappa \mathrm{B}$-mediated PI3K/AKT/mTOR signaling pathway. Food Science and Technology. In press. https://doi.org/10.1590/fst.36820.

Wu, S., Wu, B., Liu, M., Chen, Z., Wang, W., Anderson, C. S., Sandercock, P., Wang, Y., Huang, Y., Cui, L., Pu, C., Jia, J., Zhang, T., Liu, X., Zhang, S., Xie, P., Fan, D., Ji, X., Wong, K. L., Wang, L., Wu, S., Wu, B., Liu, M., Chen, Z., Wang, W., Anderson, C. S., Sandercock, P., Wang, Y., Huang, Y., Cui, L., Pu, C., Jia, J., Zhang, T., Liu, X., Zhang, S., Xie, P., Fan, D., Ji, X., Wong, K.-S. L., Wang, L., Wei, C., Wang, Y., Cheng, Y., Liu, Y., Li, X., Dong, Q., Zeng, J., Peng, B., Xu, Y., Yang, Y., Wang, Y., Zhao, G., Wang, W., Xu, Y., Yang, Q., He, Z., Wang, S., You, C., Gao, Y., Zhou, D., He, L., Li, Z., Yang, J., Lei, C., Zhao, Y., Liu, J., Zhang, S., Tao, W., Hao, Z., Wang, D., \& Zhang, S. (2019). Stroke in China: advances and challenges in epidemiology, prevention, and management. Lancet Neurology, 18(4), 394-405. http://dx.doi.org/10.1016/S1474-4422(18)30500-3. PMid:30878104. 